\title{
Cancers of Urinary System; Prevalence, Demographic
}

\author{
Zahra Tolou Ghamari (ii) ${ }^{1, *}$ \\ ${ }^{1}$ Isfahan Kidney Transplantation Research Center, Alzahra Research Centers, Isfahan University of Medical Sciences, Isfahan, Iran \\ "Corresponding author: Isfahan Kidney Transplantation Research Center, Alzahra Research Centers, Isfahan University of Medical Sciences, Isfahan, Iran. Email: \\ toloeghamari@pharm.mui.ac.ir
}

Received 2019 June 26; Revised 2019 September 05; Accepted 2019 October 04.

\begin{abstract}
Objectives: This investigation aimed to clarify the period prevalence (PP) and incidence rate (Irs) related to cancers of the urinary system in Isfahan province, Iran.

Methods: Recorded data were obtained from the Isfahan Cancer Registry. The location of cancers was distinguished from the related established topography code (C64 - C68). Period prevalence (PP) and Irs was identified per 100000 persons.

Results: There were 2117 patients with urinary system cancers. The mean age \pm SD was $63.6 \pm 14.9$ years old, which in $62 \%$ ranged between 20 and 70 years. A value of 42.5 was calculated for PP that was associated with values of 66.4 for males and 17.9 for females $(\mathrm{P}<0.001)$. The total PP corresponded to values of 33.2 for bladder, 8.1 for a kidney, 0.42 for renal pelvis, 0.36 for ureter and 0.38 for other unspecified related organs. Of these populations, the estimated living cases corresponded to 368 females and 1513 males.

Conclusions: The PP for urinary system cancers in male population was 3.7 times higher than females. There was a $23.2 \%$ increase in the Irs over the study period. These findings highlighted the advantage of a focus on the risk of urinary system diseases, its evidence based pharmacotherapy and surgical management of such patients. In this process, providing clinical drug-management has potential importance in Iran.
\end{abstract}

Keywords: Urinary System, Cancer, Kidney, Bladder, Prevalence, Iran

\section{Background}

According to a publication by Yaxley in 2016 (1), the cancers of urinary system are common and include a series of injuries encompassing small benign tumors to destructive neoplasms with high morbidity. The urinary tract is lined by epithelium extending from the renal tubule proximallly to the external urethral orifice distally. These epithelial cells are recognized as the urothelium or transitional cells. They are highly specialized cells with elasticity and variable shape. Any segment of the urothelium can be affected by malignant transformation. In the year 2008, 12.7 million cases with cancer, and 7.6 million cancerrelated deaths were reported by Globocan (2). Siegel et al., in 2013 reported (3) that advanced urothelial carcinoma accounts for about 15,000 deaths in the United States annually. The most common malignancy reported is urinary bladder cancer. The report indicates a higher ratio (2:1) of upper tract urothelial carcinoma in men than in women. The main risk factors are occupational exposure, various chemical carcinogens and cigarette smoking (4). Histological tumor classification is an established predictive factor of renal cell carcinoma (5). Cytologically and histologically, overexpression of p16INK4a has been recognized in urothelial malignancies. Therefore, there are potential implications for the clinical management of patients after the conservative treatment of non-muscle-invasive urothelial carcinoma. Furthermore, a long-term assessment of p16/Ki-67 double labeling has been revealed to distinguish high-grade urothelial cancer cells and particular individual development within a 12-month period (6). In a population with clear-cell renal cell carcinoma collecting system invasion is related to lack of prediction (7). Total existence and progression-free survival in patients with urinary system cancer could be associated with high serum levels of lactate dehydrogenase (8). Study of kidney cancer in rural Illinois showed that the kidney and renal pelvis cancer incidence was higher in urban counties whereas mortality was higher in rural counties (9). In Hong Kong in year 2012, a report indicated that $9.6 \%$ of new cancer cases were related to urological malignancy (10). Study of 198 patients with bladder cancer (BC) and 396 healthy individuals in Shiraz, Iran mentioned that a potential risk factor could be the use of opium (11).

As the essential knowledge of public health strategy, the use of epidemiologic information associated with urinary systems, is the need to provide a knowledge causes of 
disease and its pharmacotherapy management.

\section{Objectives}

As there is considerable variation in the distribution of diseases worldwide, therefore the aim of this study was to show up-to-date estimates of crude rate, incidence rates and differences in rates between men and women of urinary system cancer in Isfahan, Iran.

\section{Methods}

This retrospective study was conducted to the Isfahan Kidney Transplantation Research Center (IKTRC) and approved by the Isfahan Deputy of Research Committee via the Ethics Committee code number (295115). Cancer data was obtained from the Isfahan Cancer Registry located in deputy of health. The data considered in this study belonged to the years between March 2011 to March 2015. The cancer sites studied were characterized according to the international classification of diseases (ICD-O; third edition). All cancers were defined by topography code. For example, kidney was defined by topography code C64, renal pelvis by the topography code C65, ureter by topography code C66 and bladder by topography code C67. There was not any exclusion criterion. After removing patient name and surname, demographic data such as age and gender, final code for cancer diagnosis and date of reported cancer were recorded. Variables such as gender, being alive/dead, year of the report were expressed by frequency, percentage, period prevalence and incidence rate. The total population of Isfahan city was obtained from the Isfahan/Program and Budget Management Organization. Period prevalence was calculated as the proportion of total cases over the period of the years $2011-2015 /$ to populations at risk during the same time period $\times 100000$. Cancer incidence rate (CIR) was calculated as dividing new cases of cancer during a given time period/to populate at risk during the same time period $\times 100000$. Analysis of data was carried out using the statistical package for social science (SPSS ${ }^{\circledR}$ version 20 IBM Corp., Armonk NY, USA). An age that was a continuous variable was expressed by mean \pm standard deviation(SD) (12-20).

\section{Results}

Table 1 shows demographic and epidemiological characteristic in 2117 patients with urinary system cancers. The study population comprised of 440 females and 1677 males. The total period prevalence was calculated as 42.5 per 100000 persons (Figure 1) that corresponded to: 33.2 for bladder, 8.1 for a kidney, 0.42 for renal pelvis, 0.4 for ureter and 0.8 for other and unspecified urinary organs. With the mean age \pm standard deviation of $63.6 \pm 14.9$ years, age related to urinary system cancers in $1 \%, 62 \%$ and $37 \%$ were related to age under 20 , between 20 to 70 and 70 to 100 years of life respectively (Figure 2). Death reporteddata was associated with $11 \%$ of total cases. The rate of males to females was $83 \%$ for bladder, $77 \%$ for kidney, $62 \%$ for renal pelvis, $94 \%$ for ureter and $74 \%$ for other and unspecified urinary organs. Incidences of urinary system cancer were calculated as: 9.9 (2011 to 2012),10.5 (2012 to 2013), 9.9 (2013 to 2014) and 12.2 (2014 to 2015) per 100000 persons (Figure 3).

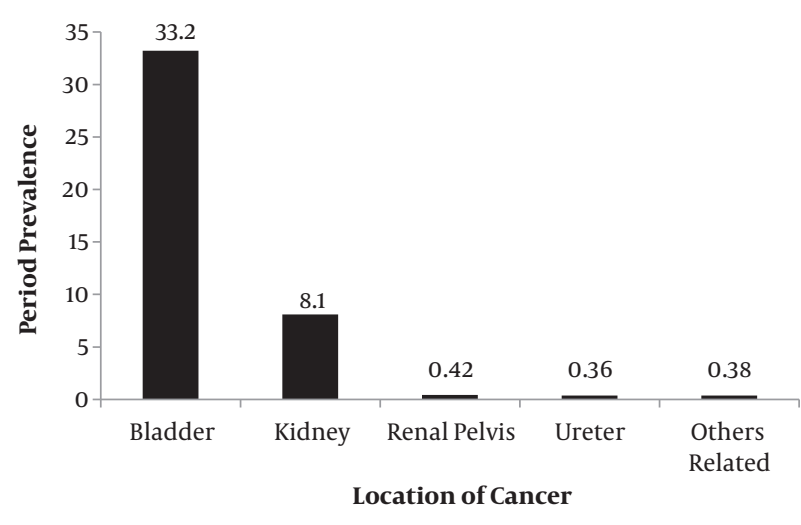

Figure 1. Cancer period prevalence according to each location within urinary system

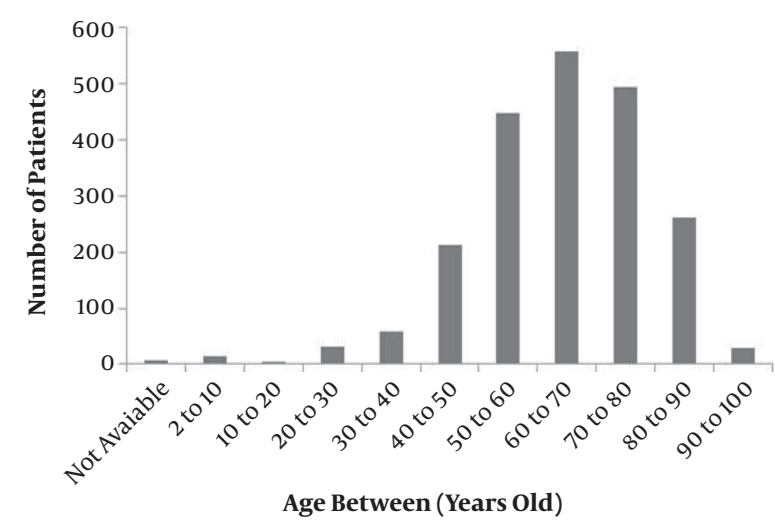

Figure 2. Distribution of age in patients with urinary system cancer 


\begin{tabular}{|c|c|c|c|c|c|c|c|c|}
\hline \multirow{2}{*}{ Sites of Cancers } & \multirow{2}{*}{ Total Cases } & \multirow{2}{*}{ Period Prevalence } & \multicolumn{3}{|c|}{ Estimated Living Cases } & \multicolumn{3}{|c|}{ Estimated Deaths } \\
\hline & & & Both Sexes & Females & Males & Both Sexes & Females & Males \\
\hline Urinary system & 2117 & 42.5 & 1881 & 368 & 1513 & 236 & 72 & 164 \\
\hline Bladder & 1655 & 33.2 & 1499 & 239 & 1260 & 156 & 41 & 115 \\
\hline Kidney & 404 & 8.1 & 348 & 72 & 276 & 56 & 21 & 35 \\
\hline Renal pelvis & 21 & 0.42 & 9 & 2 & 7 & 12 & 6 & 6 \\
\hline Ureter & 18 & 0.36 & 18 & 1 & 17 & 0 & 0 & 0 \\
\hline Other and unspecified urinary organs & 19 & 0.38 & 7 & 1 & 6 & 12 & 4 & 8 \\
\hline
\end{tabular}

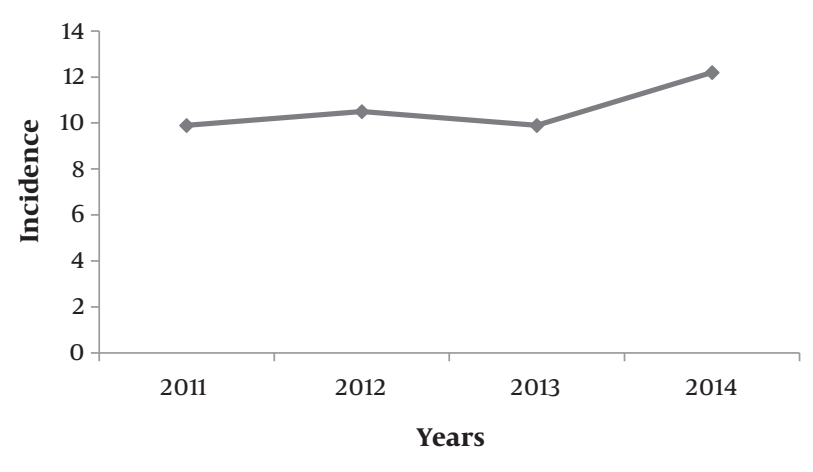

Figure 3. Incidence of urinary system cancers

\section{Discussion}

Urinary system cancers are common and impose an important cost, weight on the health system. Previous publications reported that $\mathrm{BC}$ and kidney cancers are the most common tumors of the urinary system, that make up to $5 \%$ of all cancers globally (21). As there has been diminutive evidence-based data associated with occurrence of urinary system cancers in the Iranian/Isfahan population, therefore this study conducted an analysis obtained from the population-based cancer registry.

In agreement with previous studies of western countries which specified an increasing trend toward incidence of urinary bladder and kidney cancers (22), in this study incidence of urinary system cancers $23.2 \%$ was increased between 2011 and 2015. Previous publications confirmed that, there is a change to older-in-age scattering in Iran as a developing country (23). In agreement with previous publications that mentioned the mean age of diagnosis of 65 years (24), in this study also the mean age of patients was also 63.6 years old.

The result of this study is in agreement with the Australian Institute of Health and Welfare report that confirmed bladder cancer as the most common cancers with a rise in incidence (25). De et al. in 2014 studied (26) incidence of kidney cancer between 1986 and 2007. The agestandardized incidence rate per 100,000 rose from 13.4 to 17.9 in males and 7.7 to 10.3 in females. In this study the period prevalence was ranked for BC with a value of 33.2 and 8.1 for kidney per 100000 persons respectively. The PP, among males and females was significantly different (66.4 vs. 17.9, $\mathrm{P}<0.001$ ).

The estimated deaths correlated to 236 out of 2117 (11.1\%) patients with urinary system cancers. Reported mortality in cancer of renal pelvis was $57.2 \%$ and this is in agreement with a published report from Bailey et al. in 2017, declaring that among patients with clear-cell renal cell carcinoma, collecting system invasion is associated with poor progno$\operatorname{sis}(6)$.

The results of this study showed that urinary bladder, kidney cancer followed an increasing trend in incidence, mortality and prevalence in Isfahan, Iran (14-20, 2632 ). The implications of this investigation could be mentioned as the following suggestions: (1) the health care system should provide a model-based strategy to improve access to specialized medical, pharmacological and surgical facilities; (2) consideration is needed toward the reality for scheduling health system improvements, particularly referral systems; (3) preventing significant difficulties by equality of management for patient satisfaction; (4) attention toward financial management by study of epidemiology and pharmacotherapy.

\subsection{Conclusions}

From the year 2011 to 2015, there were 2117 patients with urinary system cancers in Isfahan Province. The mean age \pm SD was $63.6 \pm 14.9$ years. In $62 \%$ of total population age ranged between 20 and 70 years. The PP was 42.5 per 100000 persons. Total PP corresponded to 66.4 for males versus 17.9 for females $(\mathrm{P}<0.001)$. The PP was 33.2 for bladder, 8.1 for a kidney, 0.42 for renal pelvis, 0.36 for ureter and 0.38 for other unspecified related organs. There were living 
cases comprised of 368 females and 1513 males. There was a $23.2 \%$ increase in the Irs over the study period.

An appropriate judgment and discussion about the trends and changes are needed to investigate the incidence of urologic cancers over time. For future plans additional research toward drug-management associated with urinary system cancers in Iran recommended.

\section{Acknowledgments}

The present work was supported by the Research Fund of Isfahan University of Medical Sciences, and extracted from project No. 295115. The author appreciates the support of cancer registry staff.

\section{Footnotes}

Authors' Contribution: Zahra Tolou-Ghamari completed this study from the idea to the final step of manuscript submission.

Conflicts of Interests: The author declares no conflict of interest.

Ethical Approval: Isfahan University of Medical Sciences supported this study. The present work was extracted from the project with ethics code number (295115).

Funding/Support: Without special financial found the present work that was extracted from the project number (295115), performed under the support of Isfahan University of Medical Sciences.

\section{References}

1. Yaxley JP. Urinary tract cancers: An overview for general practice. $J$ Family Med Prim Care. 2016;5(3):533-8. doi: 10.4103/2249-4863.197258. [PubMed: 28217578]. [PubMed Central: PMC5290755].

2. Aydin S, Boz MY. Rapid changes in the incidence of urinary system cancers in Turkey. Turk J Urol. 2015;41(4):215-20. doi: 10.5152/tud.2015.45548. [PubMed: 26623151]. [PubMed Central: PMC4621150]

3. Siegel R, Naishadham D, Jemal A. Cancer statistics, 2013. CA Cancer J Clin. 2013;63(1):11-30. doi: 10.3322/caac.21166. [PubMed: 23335087].

4. Miyazaki J, Nishiyama H. Epidemiology of urothelial carcinoma. Int J Urol. 2017;24(10):730-4. doi: 10.1111/iju.13376. [PubMed: 28543959].

5. Piaton E, Advenier AS, Carre C, Decaussin-Petrucci M, MegeLechevallier F, Hutin K, et al. p16/Ki-67 dual labeling and urinary cytology results according to the new Paris System for reporting urinary cytology: Impact of extended follow-up. Cancer Cytopathol. 2017;125(7):552-62. doi: 10.1002/cncy.21853. [PubMed: 28371465].

6. Bailey GC, Boorjian SA, Ziegelmann MJ, Westerman ME, Lohse CM, Leibovich $\mathrm{BC}$, et al. Urinary collecting system invasion is associated with poor survival in patients with clear-cell renal cell carcinoma. BJU Int. 2017;119(4):585-90. doi: 10.1111/bju.13669. [PubMed: 27696652].

7. Zhang Y, Xu T, Wang Y, Zhang H, Zhao Y, Yang X, et al. Prognostic role of lactate dehydrogenase expression in urologic cancers: A systematic review and meta-analysis. Oncol Res Treat. 2016;39(10):592-604. doi: 10.1159/000449138. [PubMed: 27710971].
8. Moch $\mathrm{H}$. [The WHO/ISUP grading system for renal carcinoma] Pathologe. 2016;37(4):355-60. German. doi: 10.1007/s00292-016-0171-y. [PubMed: 27271258].

9. Sadowski DJ, Geiger SW, Mueller GS, Zahnd WE, Alanee SR, McVary KT. Kidney cancer in rural illinois: Lower incidence yet higher mortality rates. Urology. 2016;94:90-5. doi: 10.1016/j.urology.2016.05.022. [PubMed: 27215485].

10. Yee $\mathrm{CH}, \mathrm{Ng} \mathrm{CF}$. Urological malignancy in Hong Kong: The trend and the practice. Jpn J Clin Oncol. 2015;45(12):1103-6. doi 10.1093/jjco/hyv145. [PubMed: 26450701].

11. Akbari M, Naghibzadeh-Tahami A, Khanjani N, Baneshi MR, Kamali E, Hesampour $M$, et al. Opium as a risk factor for bladder cancer: A population-based case-control study in Iran. Arch Iran Med. 2015;18(9):567-71. [PubMed: 26317596].

12. Mazdak H, Tolou-Ghamari Z. Preliminary study of prevalence for bladder cancer in Isfahan province, Iran. Arab J Urol. 2018;16(2):206-10. doi: 10.1016/j.aju.2017.11.017. [PubMed: 29892483]. [PubMed Central: PMC5992262].

13. Tolou Ghamari Z. Prevalence of lung cancer in Isfahan province, Iran J Egypt Natl Canc Inst. 2018;30(2):57-9. doi: 10.1016/j.jnci.2018.03.001. [PubMed: 29691096].

14. Tolou Ghamari Z. Thyroid cancer in Isfahan province, Iran; Prevalence and demographic characteristics. JundishapurJChronic Dis Care. 2019;8(1). e86864. doi: 10.5812/jjcdc.86864.

15. Tolou_Ghamari Z. Prevalence of stomach cancer in Isfahan Province, Iran. GulfJ Oncol. 2018;8(1).

16. Tolou-Ghamari Z. Prevalence of Skin cancer in Isfahan province, Iran Jentashapir J Health Res. 2018;9(2):82743. doi:10.5812/jjhr.82743.

17. Mazdak H, Tolou-Ghamari Z, Gholampour M. Investigation of bladder cancer incidence in Isfahan, Iran. Tehran Univ Med J. 2019;77(4):252-6.

18. Tolou-Ghamari Z. Investigation of genital system cancers prevalencein Isfahan, Iran. Indones I Cancer. 2019;13(2):25. doi: 10.33371/ijoc.v13i2.631.

19. Mazdak H, Khorrami AK, Tolou-Ghamari Z. Urethral stricture: Investigation of demographic characteristics in two tertiary hospitals in Isfahan/Iran. Am J Exp Clin Res. 2019;6(3):355-8.

20. Tolou-Ghamari Z. Prevalence of kidney, renal pelvis, and ureter cancers in Isfahan province, Iran. J Arch Mil Med. 2019;7(1-2):e95457.

21. Ferlay J, Shin HR, Bray F, Forman D, Mathers C. Globocan 2008 V1. 2, cancer incidence and mortality world-wide: IARC cancer base No. 10. Lyon, France: International Agency for Research on Cancer; 2010. Available from: http://globocan.iarc.

22. Yang Y, Xie L, Zheng JL, Tan YT, Zhang W, Xiang YB. Incidence trends of urinary bladder and kidney cancers in urban Shanghai, 1973 2005. PLoS One. 2013;8(12). e82430. doi: 10.1371/journal.pone.0082430. [PubMed: 24324788]. [PubMed Central: PMC3853415].

23. Malekmakan L, Khajehdehi P, Pakfetrat M, Malekmakan A, Mahdaviazad $\mathrm{H}$, Roozbeh J. Prevalence of chronic kidney disease and its related risk factors in elderly of southern iran: A populationbased study. ISRN Nephrol.2013;2013:427230. doi: 10.5402/2013/427230. [PubMed: 24967234]. [PubMed Central: PMC4045432].

24. Woodford C, Yao C. Essential med notes 2013. Toronto: Toronto Notes for Medical Students Inc; 2013.

25. Australian Institute of Health. Cancer survival and prevalence in Australia: Period estimates from 1982 to 2010. Canberra, Australia: AIHW; 2012.

26. De P, Otterstatter MC, Semenciw R, Ellison LF, Marrett LD, Dryer D. Trends in incidence, mortality, and survival for kidney cancer in Canada, 1986-2007. Cancer Causes Control. 2014;25(10):1271-81. doi: 10.1007/s10552-014-0427-x. [PubMed: 25034462]. [PubMed Central: PMC4194017].

27. Tolou-Ghamari Z, Shaygannejad V, Ashtari F. Preliminary study related the incidence of methylprednisolone pulse therapy in patients visited multiple sclerosis clinic located at the Isfahan Kashani hospital. Int J Prev Med. 2013;4(Suppl 2):S274-8. [PubMed: 23776737] [PubMed Central: PMC3678231]. 
28. Shaygannejad V, Tolou-Ghamari Z. What is the real fate of vitamin D in multiple sclerosis? Int JPrev Med. 2013;4(Suppl 2):S159-64. [PubMed: 23776718]. [PubMed Central: PMC3678212].

29. Tolou Ghamari Z, Mehavari Habibabadi J, Palizban AA. Evidencebased pharmacotherapy of epilepsy. Arch Neurosci. 2014;2(2). doi: 10.5812/archneurosci.18468.

30. Tolou-Ghamari Z, Tadayon F, Mazdak H. Prevalence of liver can- cer in Isfahan province, Iran. Indones J Cancer. 2018;12(2):56. doi: 10.33371/ijoc.v12i2.578

31. Tolou-Ghamari Z. Prevalence of breast cancer in Isfahan province, Iran. Womens Health Bull. 2018;5(4). e82678. doi: 10.5812/whb.82678.

32. Tolou Ghamari Z. Prevalence of stomach cancer in Isfahan province, Iran. Jundishapur J Chronic Dis Care. 2019;8(1):42-5. 